\title{
Effect of a Combination of Photodynamic Therapy and Chitosan on Streptococcus mutans (An In Vitro Study)
}

\author{
Armin Mirfasihi ${ }^{1}$, Beheshteh Malek Afzali ${ }^{2}$, Hosna Ebrahimi Zadeh ${ }^{3}$, Khashayar Sanjari ${ }^{*}{ }^{*}$ Maziar Mir $^{5}$ \\ ${ }^{1}$ Assistant Professor, Periodontology Department, Shahid Beheshti University of Medical Sciences, Tehran, Iran \\ ${ }^{2}$ Associate Professor, Department of Pediatric Dentistry, Dental Research Center, Research Institute of Dental Science, \\ Department of Pediatric Dentistry, Dental School, Shahid Beheshti University of Medical Sciences, Tehran, Iran \\ ${ }^{3}$ Dental Research Center, Restorative Department, School of Dentistry, Shahid Beheshti University of Medical Sciences, \\ Tehran, Iran \\ ${ }^{4}$ Department of Pediatric Dentistry, School of Dentistry, Arak University of Medical Sciences, Arak, Iran \\ ${ }^{5}$ Department of Conservative Dentistry, RWTH Aachen Hospital \& Deutsche Gesellschaft fur laserzahnheilkunde (DGL), \\ Aachen Klinkum, Pauwelsstr.30, 52074 Aachen, Germany
}

\section{*Correspondence to Khashayar Sanjari, Department of Pediatric Dentistry, School of Dentistry, Arak University of Medical Sciences, Arak, Iran Email: \\ khashayarsanjari@gmail.com}

Published online October 3 2020

\begin{abstract}
Introduction: This study aimed to assess the effect of photodynamic therapy (PDT) and chitosan separately and in combination on Streptococcus mutans.

Methods: This in vitro experimental study evaluated 216 microbial samples in 6 groups. First, $5 \mu \mathrm{L}$ of 0.5 McFarland standard suspension of $S$. mutans was added to each well of an ELISA microplate; 100 $\mu \mathrm{L}$ of Mueller Hinton broth was also added to each well; 180 wells contained $S$. mutans suspension while 36 wells were devoid of bacteria. Group 1 served as the negative control and had no bacteria. Group 2 served as the positive control and S. mutans in the positive control wells did not undergo any intervention. In groups 3 and 4, PDT with a $50 \mathrm{~mW}$ low-level laser was performed for 30 and 40 seconds respectively. In group $5,3 \mathrm{mg} / \mathrm{mL}$ of chitosan $(100 \mu \mathrm{L})$ was used. In group $6,3 \mathrm{mg} / \mathrm{mL}$ $(100 \mu \mathrm{L})$ of chitosan was used in combination with PDT (50 mW laser for 30 seconds). The laser was irradiated under aseptic conditions at a $660 \mathrm{~nm}$ wavelength with $50 \mathrm{~mW}$ power. Data were analyzed using one-way ANOVA and Tukey's test.

Results: PDT combined with chitosan showed maximum bactericidal effect followed by PDT for 40 seconds and chitosan groups $(P<0.05)$. PDT for 30 seconds showed a minimum bactericidal effect $(P<0.05)$. All pairwise comparisons revealed significant differences $(P<0.001)$.

Conclusion: Chitosan and PDT alone can be used to decrease the $S$. mutans count. However, their combined use has a greater bactericidal effect on S. mutans.

Keywords: Streptococcus mutans; Chitosan; Photodynamic therapy.
\end{abstract}

\section{Introduction}

Despite the advances in caries control programs and increased use of fluoride, the prevalence of dental caries is still high worldwide. ${ }^{1,2}$ Dental caries can cause pain and affect patients' quality of life. ${ }^{3,4}$ Dental caries has a multifactorial origin and is caused by the interaction of some internal factors such as decreased salivary flow, tooth surface morphology, poor nutritional status and hormonal conditions and external factors such as microbial flora, poor oral hygiene and low access to fluoride.

Biofilm formation is a biological process mediated by the attachment of oral bacteria to tooth surfaces and their proliferation. Dental biofilm forms following the adhesion of planktonic bacteria to the pellicle covering the tooth surface. ${ }^{6}$ Only limited bacteria can attach to tooth surfaces such as Streptococcus mutans and lactobacilli. ${ }^{7,8}$ S. mutans is one of the main causes of dental caries and is the target of the majority of preventive strategies. ${ }^{9}$ Prevention is the most efficient method of caries control. ${ }^{10}$ Several antimicrobial agents such as xylitol, ${ }^{11}$ chlorhexidine, ${ }^{12}$ fluoride ${ }^{13}$ and chitosan have been introduced for caries prevention. Chitosan is a polysaccharide composed of glucosamine and $\mathrm{N}$-acetyl glucosamine copolymers. ${ }^{14}$ Chitosan could be synthesized by partial deacetylation of chitin. Chitosan is formed of a series of polymers that have different molecular weight, viscosity and deacetylation rates. ${ }^{15}$ Chitosan is biocompatible and has chelating capability. ${ }^{16}$ Chitosan can induce the nucleation of crystals on the dentin surface and enhance the mineralization of demineralized enamel by the use of calcium and phosphate. Chitosan biopolymers are used

Please cite this article as follows: Mirfasihi A, Malek Afzali B, Ebrahimi Zadeh H, Sanjari K, Mir M. Effect of a combination of photodynamic therapy and chitosan on Streptococcus mutans (an in vitro study). J Lasers Med Sci. 2020;11(4):405-410. doi:10.34172/jlms.2020.64. 
for the treatment of carious dentin. ${ }^{17}$ Chitosan has strong bactericidal activity and is not toxic for mammals. ${ }^{18}$ It has anti-tumor and wound-healing properties and is mucoadhesive..$^{19}$ It has antibacterial and antifungal properties as well. ${ }^{20}$ Its antimicrobial properties are related to its attachment to bacterial DNA. ${ }^{21}$ It also increases the bacterial membrane permeability and causes the leakage of cellular components. It interferes with mRNA synthesis and subsequently prevents protein synthesis. ${ }^{22}$ The inhibitory effect of chitosan on streptococci has been previously reported. ${ }^{23}$ Chitosan interferes with the adhesion of $S$. mutans to dental biofilm and prevents biofilm maturation. ${ }^{24}$

Photodynamic therapy (PDT) is a non-invasive modality that uses a low-level laser to prevent the growth and proliferation of bacteria such as S. mutans. It is commonly used in periodontal therapy. In PDT, visible light is used to activate a photosensitizer, which produces reactive oxygen species upon activation, causing phototoxicity. The efficacy of PDT depends on a number of factors such as type of visible light, laser settings, and reaction with the photosensitizer. ${ }^{25}$ Free radicals produced in PDT have toxic effects on the bacteria but not on host cells in most of the cases. ${ }^{26}$ This minimally invasive modality is effective against resistant bacterial species. Also, it could be used in the management of solid cancers or ocular vascularization diseases. ${ }^{27,28}$ It does not cause any unwanted damage to tissue. ${ }^{29}$ The efficacy of photosensitizers depends on their dosage and site of application. Methylene blue is one of the commonly used materials as a photosensitizer. ${ }^{30}$

Several antibacterial agents such as chlorhexidine, metronidazole and quaternary ammonium compounds are used for the elimination of cariogenic microorganisms and the prevention of dental caries, but they have side effects such as staining, increasing calculus formation and causing diarrhea by changing the normal microbial flora of the gastrointestinal system. ${ }^{31}$ Thus, there is a need for new strategies to prevent the growth and proletarian of $S$. mutans and dental caries. Studies on the use of chitosan for the prevention of caries and its effect on S. mutans are limited, and the available ones have reported conflicting results.

There are a large number of studies on PDT as a conservative antibacterial modality. However, they are widely variable in methodology and sample size. Therefore, it is impossible to make a definite conclusion regarding the efficacy of PDT in the elimination of cariogenic bacteria. Thus, this study aimed to assess the effects of PDT, chitosan and a combination of the two on S. mutans.

\section{Materials and Methods}

In this in vitro experimental study, the sample size was calculated to be 216 samples ( $n=36$ in each group) according to a study by Camacho-Alonso et al, ${ }^{32}$ assuming alpha $=0.05$, beta $=0.2$ and power of $80 \%$ using PASS 2015 software.

The microorganisms used in this study were the standard strains of S. mutans ATCC 3198 obtained from the microbial bank of the microbiology laboratory of the School of Medicine at Shahid Beheshti University of Medical Sciences and they were cultured on blood agar. They were then incubated at $37^{\circ} \mathrm{C}$ for 48 hours in anaerobic conditions $(\mathrm{CO} 2, \mathrm{H}$, and $\mathrm{N})$ to decrease variability and confirm the phenotype of cells growth After the formation of colonies, $0.5 \mathrm{McF}$ arland standard suspension of $S$. mutans was prepared. The cultures that were incubated were then homogenized with a vortexer, and then their optical density (OD) was measured with a microplate reader on a wavelength of $600 \mathrm{~nm}$. Each $1 \mathrm{cc}$ of the suspension contained $1.5 \times 10^{8}$ bacteria. Next, 100 $\mu \mathrm{L}$ of Mueller-Hinton broth culture medium (Thermo Scientific, Waltham, MA, USA) was added to each well of an ELISA microplate (Streptavidin ELISA Plate Safety Data Sheet - SDS) (Figure 1); $5 \mu \mathrm{L}$ of 0.5 McFarland standard suspension of $S$. mutans was also added to 36 wells as the negative control. These wells were devoid of bacteria. The study groups were as follows:

Group 1 served as the negative control and was devoid of bacteria. Group 2 served as the positive control and the wells contained $S$. mutans that did not undergo any intervention. In group 3, PDT with a low-level laser with $50 \mathrm{~mW}$ power was performed for 30 seconds $(1.5 \mathrm{~J})$. In group 4, PDT with $50 \mathrm{~mW}$ power was performed for 40 seconds (2 J). In group $5,3 \mathrm{mg} / \mathrm{mL}$ of chitosan in an amount of $100 \mu \mathrm{L}$ was added to the wells according to a study by Camacho-Alonso et al. ${ }^{32}$ In group $6,3 \mathrm{mg} / \mathrm{mL}$ of chitosan $(100 \mu \mathrm{L})$ was used in addition to PDT with 50 $\mathrm{mW}$ power for 30 seconds (1.5 J). Thirty-six samples were evaluated in each group.

The laser was irradiated under aseptic conditions at a $660 \mathrm{~nm}$ wavelength (Hager and Werken $\mathrm{GmbH}$ and Co. Duisburg, Germany) (Figure 2) under a laminar flow hood. The calibration is evaluated by a power meter. The spot area (laser aperture) was $0.38 \mathrm{~cm}^{2}$. The tip of the laser handpiece was fixed in a vertical position at the opening of the well. To prevent accidental irradiation of adjacent wells and bias in the results, two empty wells were considered between the study wells. The plate was covered with a

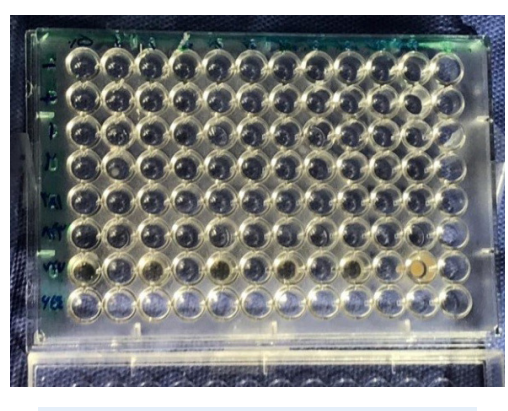

Figure 1. ELISA Microplate for Samples. 
black shield that had a hole in it corresponding to the size of the opening of one well $(7 \mathrm{~mm})$ to prevent accidental irradiation of other wells.

Methylene blue (100 $\mu \mathrm{L}$; Merck, Germany) in $0.01 \%$ concentration was used as a photosensitizer in PDT. Methylene blue was added to each well and was irradiated with the laser after 3 minutes (Figure 3 ). The interval between the laser aperture and the sample surface was fixed at $1 \mathrm{~mm}$ in all study groups.

Chitosan paste with low viscosity (Merck, Germany) was dissolved in $3 \mathrm{mg} / \mathrm{mL}$ of $1 \%$ acetic acid (Merck, Germany) and was added to each well in an amount of $100 \mu \mathrm{L}$.

After the interventions, $0.02 \mathrm{cc}$ of the contents of each well was removed by a sterile loop and cultured on the blood agar culture medium (Figure 4 ). They were incubated at $37^{\circ} \mathrm{C}$ for 24 hours. After incubation, the number of colony-forming units per milliliter (CFU/mL) was determined.

Normal distribution of data was evaluated using the Kolmogorov-Smirnov test. The homogeneity of variances was evaluated using the Levene's test. The groups were compared using one-way ANOVA. Pairwise comparisons were carried out using the Tukey's HSD test. The level of significance was set at 0.05 . All statistical analyses were carried out using Excel 2013 software.

\section{Results}

The Kolmogorov-Smirnov test confirmed the normal

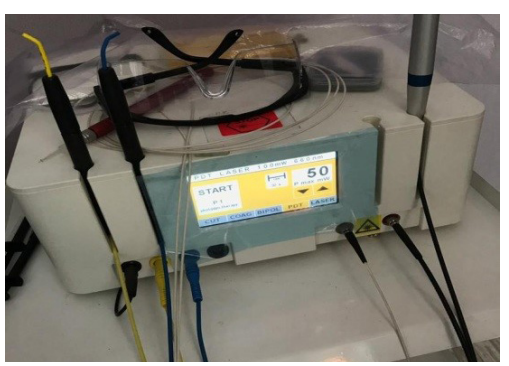

Figure 2. Photodynamic Therapy Device.

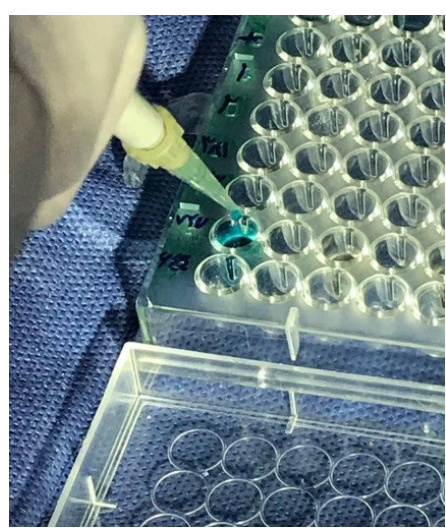

Figure 3. Methylene Blue Added to Each Well.

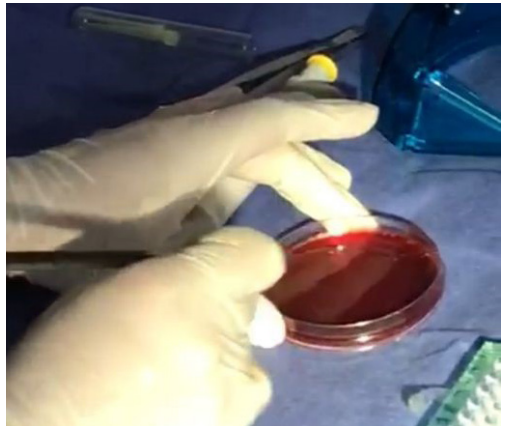

Figure 4. Blood Agar Culture.

distribution of data in all groups $(P>0.05)$. The homogeneity of variances was also confirmed by the Levene's test $(P>0.05)$. Non-treatment groups (negative and positive control groups) were chosen to standardize the study protocol. The s. mutans count was zero in the negative control group. The positive control group showed the highest number of $\mathrm{CFU} / \mathrm{mL}$.

Table 1 shows the number of colonies in the four treatment groups, indicative of the bactericidal effects of the four modalities. One-way ANOVA showed a significant difference in the bactericidal effects of the four groups $(P<0.001)$. Thus, pairwise comparisons of the groups were performed using the Tukey's HSD test. The results showed a maximum bactericidal effect in the combination of PDT and chitosan followed by PDT for 40 seconds and chitosan groups. PDT for 30 seconds showed a minimum bactericidal effect (Figure 5). All pairwise comparisons yielded significant differences $(P<0.001$ for all six comparisons, Table 2).

\section{Discussion}

This study assessed the effect of PDT, chitosan and a combination of the two on S. mutans. The results revealed that PDT plus chitosan had maximum bactericidal effect followed by PDT for 40 seconds and chitosan groups. A minimum bactericidal effect was noted after PDT for 30 seconds. All pairwise comparisons yielded significant differences $(P<0.001)$.

Zheng and $\mathrm{Zhu}^{33}$ discussed that the mechanism of action of chitosan in the inhibition of bacterial growth is based on modifying the bacterial cell wall and permeability of the cell membrane. The addition of this biopolymer to toothpaste can prevent the attachment of S. mutans to tooth surfaces. ${ }^{34}$ Abedian et $\mathrm{al}^{35}$ found that chitosan can inhibit the growth and proliferation of S. mutans. Also, it prevents biofilm formation on tooth surfaces. Costa et al. ${ }^{36}$ evaluated mouthwashes containing chitosan and concluded that it can decrease the count of S. mutans. Chen and Chung ${ }^{37}$ Fujiwara et al, ${ }^{38}$ Kawakita et $\mathrm{al},{ }^{39}$ and de $\mathrm{Paz}$ et $\mathrm{al}^{40}$ used chitosan dissolved in water as a mouthwash against $S$. mutans and found similar results. Hayashi et $\mathrm{al}^{23}$ evaluated the effect of chitosan chewing gum on S. mutans and reported the growth 
Table 1. Number of Colonies in the Four Experimental Groups, Indicative of the Bactericidal Effects of the Four Modalities ( $\mathrm{n}=36$ )

\begin{tabular}{|c|c|c|c|c|c|c|}
\hline \multirow{2}{*}{ Group } & \multirow{2}{*}{$\begin{array}{c}\text { Maximum } \\
\text { CFU/MI }\end{array}$} & \multirow{2}{*}{$\begin{array}{c}\text { Minimum } \\
\text { CFU/MI }\end{array}$} & \multicolumn{2}{|c|}{$95 \% \mathrm{Cl}$} & \multirow{2}{*}{ Standard Deviation } & \multirow{2}{*}{ Mean } \\
\hline & & & Upper Bound & Lower Bound & & \\
\hline PDT for 30 seconds & 3000.00 & 2100.00 & 2560.5859 & 2431.0808 & 191.37659 & 2495.8333 \\
\hline PDT for 40 seconds & 1350.00 & 900.00 & 1175.9403 & 1090.7264 & 125.92515 & 1133.3333 \\
\hline PDT with chitosan & 750.00 & 200.00 & 440.0700 & 346.0411 & 138.95157 & 393.0556 \\
\hline Chitosan alone & 2250.00 & 1500.00 & 1868.9009 & 1761.6546 & 158.48364 & 1815.2778 \\
\hline
\end{tabular}

Table 2. Pairwise Comparisons of the Groups in Terms of the Colony Count (Bactericidal Effects)

\begin{tabular}{|c|c|c|c|c|}
\hline Group (I) & Group (J) & Standard Error & Mean Difference & $P$ Value \\
\hline \multirow{3}{*}{ PDT for 30 seconds } & PDT for 40 seconds & 36.68688 & 1362.50000 & 0.000 \\
\hline & PDT with chitosan & 36.68688 & 2102.77778 & 0.000 \\
\hline & Chitosan & 36.68688 & 680.55556 & 0.000 \\
\hline \multirow{2}{*}{ PDT for 40 seconds } & PDT with chitosan & 36.68688 & 740.27778 & 0.000 \\
\hline & Chitosan & 36.68688 & -681.94444 & 0.000 \\
\hline PDT with chitosan & Chitosan & 36.68688 & -1422.22222 & 0.000 \\
\hline
\end{tabular}

inhibition of $S$. mutans and reduction of its count in the saliva following the use of chitosan chewing gum. In the present study, chitosan significantly decreased the count of $S$. mutans, which was in line with the findings of the abovementioned studies. ${ }^{23,37-40}$

Previous studies on the bactericidal effects of PDT did not use the same protocol, and wide variability exists in the wavelength of light, its energy density and duration of exposure. ${ }^{25-27}$ In the present study, $50 \mathrm{~mW}$ power was used and the radiation time was 30 and 40 seconds. Chitosan was used in combination with PDT in this study and yielded positive results, showing a maximum bactericidal effect on $S$. mutans due to the synergistic effect of chitosan and PDT. Fabio et $a .^{41}$ evaluated the effect of chitosan plus PDT on Candida albicans and concluded that the addition of chitosan to methylene blue did not enhance the antifungal effects of PDT. Their results were different from our findings, which may be due to the fact that different microorganisms were evaluated in the two studies. Chien et $\mathrm{al}^{42}$ used chitosan to enhance the effects of PDT on Candida albicans and reported the optimal efficacy of this combined modality.

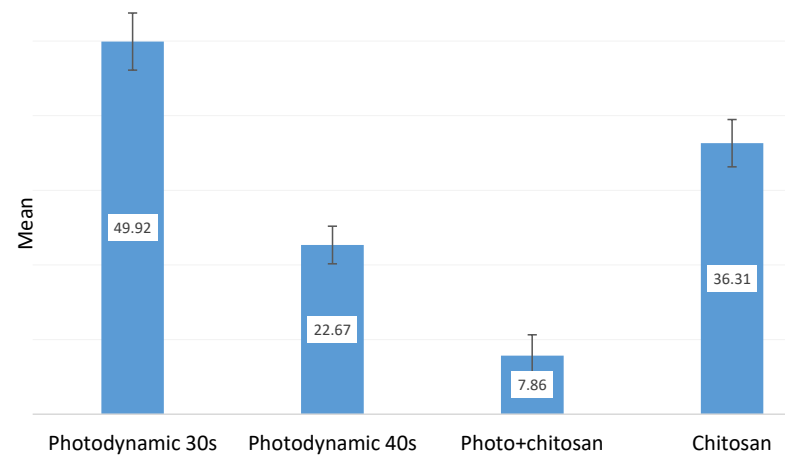

Figure 5. Comparison of the Bactericidal Effect of Different Therapeutic Methods.
The difference between their results and those of Fabio et $\mathrm{al}^{41}$ may be due to different sample sizes. Peng et $\mathrm{al}^{43}$ evaluated the chitosan hydrogels to enhance the efficacy of PDT against Staphylococcus aureus, Aggregatibacter actinomycetemcomitans and Porphyromonas gingivalis and concluded that the combination of chitosan and PDT enhanced the efficacy of PDT for the treatment of periodontal pockets; their results were in line with our findings.

Camacho-Alonso et $\mathrm{al}^{32}$ evaluated the effect of chitosan plus PDT on Enterococcus faecalis, which is the main culprit responsible for treatment-resistant endodontic infections. They observed that this combination caused a greater reduction in the bacterial count compared with the use of each modality alone. This result was in agreement with ours.

Gong et $\mathrm{al}^{44}$ assessed the effects of PDT on S. mutans and showed that PDT significantly decreased the $S$. mutans count, which was in line with our results. Alves et $\mathrm{al}^{45}$ evaluated the antimicrobial effects of PDT on carious lesions of primary molars and reported that PDT can serve as an adjunct to caries removal and restoration of teeth for the reduction of the $S$. mutans count. Azizi et $\mathrm{al}^{46}$ evaluated the effects of PDT on S. mutans. They used 660 and 810 $\mathrm{nm}$ wavelengths of laser with 100 and $40 \mathrm{~mW}$ power for 60 seconds and concluded that PDT can eradicate $S$. mutans colonies. Fekrazad et $\mathrm{al}^{47}$ concluded that PDT can significantly decrease the count of S. mutans in children's saliva with early childhood caries immediately after the intervention. Similar results were reported by Beytollahi et $\mathrm{al}^{48}$ and Rolim et $\mathrm{al}^{49}$ These results were in agreement with our findings and highlighted the optimal efficacy of PDT for the elimination of $S$. mutans. We irradiated a lowlevel laser for 30 and 40 seconds in our study. Considering the short duration of laser irradiation in our study, this protocol can be used for pediatric patients with poor cooperation. However, most previous studies irradiated a 
laser for longer periods of time for periodontal purposes in adults. Further studies are required on ideal laser parameters to achieve the best bactericidal effects. In vitro design, which limits the generalizability of the results to the clinical setting, was a limitation of this study. Future in vivo studies are required to increase the generalizability of the results to the clinical setting. Also, the efficacy of higher concentrations of chitosan should be evaluated in future studies.

\section{Conclusion}

Chitosan and PDT can be used as alternative modalities for the reduction of the $S$. mutans count. Also, a combination of the two showed a greater bactericidal effect on the $S$. mutans count. Thus, considering its non-invasiveness, this innovative combination technique can be used to control caries in pediatric patients.

\section{Ethical Considerations}

This study was approved by the ethics committee of Shahid Beheshti University of Medical Sciences (IR. SBMU.DRC.REC.1397.026).

\section{Conflict of Interests}

The authors declare that they have no conflict of interest.

\section{Funding Statement}

This research did not receive any specific grant from funding agencies in the public, commercial, or not-forprofit sectors.

\section{References}

1. Nokhbatolfoghahaie H, AliKhasi M, Chiniforush N, Khoei F, Safavi N, Yaghoub Zadeh B. Evaluation of accuracy of DIAGNOdent in diagnosis of primary and secondary caries in comparison to conventional methods. J Lasers Med Sci. 2013;4(4):159-67.

2. Loiola ABA, Aires CP, Curylofo-Zotti FA, RodriguesJunior AL, Souza-Gabriel AE, Corona SAM. The impact of $\mathrm{CO}_{2}$ laser treatment and acidulated phosphate fluoride on enamel demineralization and biofilm formation. J Lasers Med Sci. 2019;10(3):200-206. doi: 10.15171/jlms.2019.32.

3. Petersen PE. The World Oral Health Report 2003: continuous improvement of oral health in the 21 st century-the approach of the WHO Global Oral Health Programme. Community Dent Oral Epidemiol. 2003;31 Suppl 1:3-23. doi:10.1046/j.2003.com122.x

4. Broadbent JM, Thomson WM, Poulton R. Trajectory patterns of dental caries experience in the permanent dentition to the fourth decade of life. J Dent Res. 2008;87(1):69-72. doi: 10.1177/154405910808700112.

5. Lenander-Lumikari M, Loimaranta V. Saliva and dental caries. Adv Dent Res. 2000;14:40-7. doi: 10.1177/08959374000140010601.

6. Arendás K, Herczegh A, Kerémi B, Tóth Z. [Complete attendance of a caries risk patient]. Fogorv $S z$. 2013;106(1):17-21. [In Hungarian].

7. Takahashi Y, Urano-Tashiro Y, Konishi K. [Adhesins of oral streptococci]. Nihon Saikingaku Zasshi. 2013;68(2):283-93.
[In Japanese]. doi: 10.3412/jsb.68.283.

8. Selwitz RH, Ismail AI, Pitts NB. Dental caries. Lancet. 2007;369(9555):51-9. doi: 10.1016/S0140-6736(07)600312.

9. Babu V, Hegde S, Bhat S, Sargod S. Evaluation of efficacy of three different commercially available kit for chairside cariogenic bacteria test - Caries Risk Test, Saliva-check Mutans and CariScreen. Cureus. 2019;11(12): e6504. doi: 10.7759/cureus.6504.

10. Peckham S, Awofeso N. Water fluoridation: a critical review of the physiological effects of ingested fluoride as a public health intervention. ScientificWorldJournal. 2014;2014:293019. doi: 10.1155/2014/293019.

11. Watthanasaen S, Merchant AT, Luengpailin S, Chansamak N, Pisek A, Pitiphat W. Xylitol-containing chewing gum for caries prevention in students with disabilities: A randomised trial. Oral Health Prev Dent. 2017;15(6):51927. doi: 10.3290/j.ohpd.a39668.

12. Silva LA, Romualdo PC, Silva RA, Souza-Gugelmin MC, Pazelli LC, De Freitas AC, et al. Antibacterial effect of calcium hydroxide with or without chlorhexidine as intracanal dressing in primary teeth with apical periodontitis. Pediatr Dent. 2017;39(1):28-33.

13. Wolff MS, Schenkel AB. The anticaries efficacy of a $1.5 \%$ arginine and fluoride toothpaste. Adv Dent Res. 2018;29(1):93-7. doi: 10.1177/0022034517735298.

14. Illum L. Chitosan and its use as a pharmaceutical excipient. Pharm Res. 1998;15(9):1326-1331. doi: 10.1023/a:1011929016601.

15. Singla AK, Chawla M. Chitosan: Some pharmaceutical and biological aspects--an update. J Pharm Pharmacol. 2001;53(8):1047-67. doi: 10.1211/0022357011776441.

16. Chen Z, Cao S, Wang H, Li Y, Kishen A, Deng X, et al. Biomimetic remineralization of demineralized dentine using scaffold of CMC/ACP nanocomplexes in an in vitro tooth model of deep caries. PLoS One. 2015;10(1):e0116553. doi: 10.1371/journal.pone.0116553.

17. Raafat D, Sahl HG. Chitosan and its antimicrobial potential-a critical literature survey. Microb Biotechnol. 2009;2(2):186-201. doi: 10.1111/j.1751-7915.2008.00080.x.

18. Liu XF, Guan YL, Yang DZ, Li Z, Yao KD. Antibacterial action of chitosan and carboxymethylated chitosan. J Appl Polym Sci. 2001;79(7):1324-35. doi: 10.1002/1097-4628(20010214)79:7<1324::AID APP210>3.0.CO;2-L.

19. Dutta PK, Dutta J, Tripathi VS. Chitin and chitosan: Chemistry, properties and applications. J Sci Ind Res (India). 2004;63:20-31.

20. Chung YC, Wang HL, Chen YM, Li SL. Effect of abiotic factors on the antibacterial activity of chitosan against waterborne pathogens. Bioresour Technol. 2003;88(3):17984. doi: 10.1016/s0960-8524(03)00002-6.

21. Chung YC, Chen CY. Antibacterial characteristics and activity of acid-soluble chitosan. Bioresour Technol. 2008;99(8):2806-14. doi: 10.1016/j.biortech.2007.06.044.

22. Helander IM, Nurmiaho-Lassila EL, Ahvenainen R, Rhoades J, Roller S. Chitosan disrupts the barrier properties of the outer membrane of Gram-negative bacteria. Int $J$ Food Microbiol. 2001;71(2-3):235-44. doi: 10.1016/s01681605(01)00609-2.

23. Hayashi Y, Ohara N, Ganno T, Yamaguchi K, Ishizaki T, Nakamura $\mathrm{T}$, et al. Chewing chitosan-containing gum effectively inhibits the growth of cariogenic bacteria. 
Arch Oral Biol. 2007;52(3):290-4. doi: 10.1016/j. archoralbio.2006.10.004.

24. Costa EM, Silva S, Tavaria FK, Pintado MM. Study of the effects of chitosan upon Streptococcus mutans adherence and biofilm formation. Anaerobe. 2013;20:27-31. doi: 10.1016/j.anaerobe.2013.02.002.

25. Santin GC, Oliveira DS, Galo R, Borsatto MC, Corona SA. Antimicrobial photodynamic therapy and dental plaque: a systematic review of the literature. ScientificWorldJournal. 2014;2014:824538 . doi: 10.1155/2014/824538.

26. Mahmoudi H, Bahador A, Pourhajibagher M, Alikhani MY. Antimicrobial Photodynamic Therapy: An effective alternative approach to control bacterial infections. J Lasers Med Sci. 2018;9(3):154-160. doi: 10.15171/jlms.2018.29.

27. Schneider M, Kirfel G, Berthold M, Frentzen M, Krause F, Braun A. The impact of antimicrobial photodynamic therapy in an artificial biofilm model. Lasers Med Sci. 2012;27(3):615-20. doi: 10.1007/s10103-011-0998-7.

28. Gambhir RS, Sogi GM, Nirola A, Brar R, Sekhon T, Kakar H. Nanotechnology in dentistry: Current achievements and prospects. J Orofac Sci. 2013;5(1):9-14.

29. Asnaashari M, Eghbal MJ, Sahba Yaghmayi A, Shokri M, Azari-Marhabi S. Comparison of antibacterial effects of photodynamic therapy, modified triple antibiotic paste and calcium hydroxide on root canals infected with Enterococcus faecalis: An in vitro study. J Lasers Med Sci. 2019;10(Suppl 1):S23-S29. doi: 10.15171/jlms.2019.S5.

30. Khorsandi K, Chamani E, Hosseinzadeh G, Hosseinzadeh R. Comparative study of photodynamic activity of methylene blue in the presence of salicylic acid and curcumin phenolic compounds on human breast cancer. Lasers Med Sci. 2019;34(2):239-246. doi: 10.1007/s10103018-2571-0.

31. Bernardes WA, Lucarini $R$, Tozatti MG, Souza MG, Andrade Silva ML, da Silva Filho AA, et al. Antimicrobial activity of Rosmarinus officinalis against oral pathogens: relevance of carnosic acid and carnosol. Chem Biodivers. 2010;7(7):1835-40. doi: 10.1002/cbdv.200900301.

32. Camacho-Alonso F, Julián-Belmonte E, Chiva-García F, Martínez-Beneyto Y. Bactericidal efficacy of photodynamic therapy and chitosan in root canals experimentally infected with Enterococcus faecalis: An in vitro study. Photomed Laser Surg. 2017;35(4):184-9. doi: 10.1089/pho.2016.4148.

33. Zheng LY, Zhu JF. Study on antimicrobial activity of chitosan with different molecular weights. Carbohydr Polym. 2003;54(4):527-30. doi: 10.1016/j.carbpol.2003.07.009.

34. Tarsi R, Muzzarelli RA, Guzmán CA, Pruzzo C. Inhibition of Streptococcus mutans adsorption to hydroxyapatite by lowmolecular-weight chitosans. J Dent Res. 1997;76(2):665-72. doi: 10.1177/00220345970760020701.

35. Abedian Z, Jenabian N, Moghadamnia AA, Zabihi E, Tashakorian H, Rajabnia M, et al. Antibacterial activity of high-molecular-weight and low-molecular-weight chitosan upon oral pathogens. J Conserv Dent. 2019;22(2):169-74. doi: 10.4103/JCD.JCD_300_18.

36. Costa EM, Silva S, Madureira AR, Cardelle-Cobas A, Tavaria FK, Pintado MM. A comprehensive study into the impact of a chitosan mouthwash upon oral microorganism's biofilm formation in vitro. Carbohydr Polym. 2014;101:1081-6. doi: 10.1016/j.carbpol.2013.09.041.

37. Chen CY, Chung YC. Antibacterial effect of water-soluble chitosan on representative dental pathogens Streptococcus mutans and Lactobacilli brevis. J Appl Oral Sci. 2012;20(6):620-7. doi: 10.1590/S1678-77572012000600006.

38. Fujiwara M, Hayashi Y, Ohara N. Inhibitory effect of watersoluble chitosan on growth of Streptococcus mutans. New Microbiol. 2004;27(1):83-6.

39. Kawakita ER, Ré AC, Peixoto MP, Ferreira MP, RicominiFilho AP, Freitas O, et al. Effect of chitosan dispersion and microparticles on older Streptococcus mutans biofilms. Molecules. 2019;24(9):1808. doi: 10.3390/ molecules 24091808 .

40. Chávez de Paz LE, Resin A, Howard KA, Sutherland DS, Wejse PL. Antimicrobial effect of chitosan nanoparticles on Streptococcus mutans biofilms. Appl Environ Microbiol. 2011;77(11):3892-5. doi: 10.1128/AEM.02941-10.

41. Fabio CA, Yolanda MB, Carmen GM, Francisco C, Antonio Julián B, Leonor PL, et al. Use of photodynamic therapy and chitosan for inactivation of Candida albicans in a murine model. J Oral Pathol Med. 2016;45(8):627-33. doi: 10.1111/jop.12435.

42. Chien HF, Chen CP, Chen YC, Chang PH, Tsai T, Chen CT. The use of chitosan to enhance photodynamic inactivation against Candida albicans and its drug-resistant clinical isolates. Int J Mol Sci. 2013;14(4):7445-56. doi: 10.3390/ ijms14047445.

43. Peng PC, Hsieh CM, Chen CP, Tsai T, Chen CT. Assessment of photodynamic inactivation against periodontal bacteria mediated by a chitosan hydrogel in a 3D gingival model. Int J Mol Sci. 2016;17(11):1821. doi: 10.3390/ijms17111821.

44. Gong J, Park H, Lee J, Seo H, Lee S. Effect of photodynamic therapy on multispecies biofilms, including Streptococcus mutans, Lactobacillus casei, and Candida albicans. Photobiomodul Photomed Laser Surg. 2019;37(5):282-7. doi: 10.1089/photob.2018.4571.

45. Alves LV, Curylofo-Zotti FA, Borsatto MC, de Souza Salvador SL, Valério RA, Souza-Gabriel AE, et al. Influence of antimicrobial photodynamic therapy in carious lesion. Randomized split-mouth clinical trial in primary molars. Photodiagnosis Photodyn Ther. 2019;26:124-30. doi: 10.1016/j.pdpdt.2019.02.018.

46. Azizi A, Shademan S, Rezai M, Rahimi A, Lawaf S. Effect of photodynamic therapy with two photosensitizers on Streptococcus mutants: in vitro study. Photodiagnosis Photodyn Ther. 2016;16:66-71. doi: 10.1016/j. pdpdt.2016.08.002.

47. Fekrazad R, Seraj B, Chiniforush N, Rokouei M, Mousavi N, Ghadimi S. Effect of antimicrobial photodynamic therapy on the counts of salivary Streptococcus mutans in children with severe early childhood caries. Photodiagnosis Photodyn Ther. 2017;18:319-22. doi: 10.1016/j.pdpdt.2017.03.007.

48. Beytollahi L, Pourhajibagher M, Chiniforush N, Ghorbanzadeh R, Raoofian R, Pourakbari B, et al. The efficacy of photodynamic and photothermal therapy on biofilm formation of Streptococcus mutans: an in vitro study. Photodiagnosis Photodyn Ther. 2017;17:56-60. doi: 10.1016/j.pdpdt.2016.10.006.

49. Rolim JP, de-Melo MA, Guedes SF, Albuquerque-Filho FB, de Souza JR, Nogueira NA, et al. The antimicrobial activity of photodynamic therapy against Streptococcus mutans using different photosensitizers. J Photochem Photobiol B. 2012;106:40-6. doi: 10.1016/j.jphotobiol.2011.10.001. 